\title{
Letter-to-the-Editor
}

\section{Monitoring Child Undernutrition at National Levels Before and After the Economic and Food Crisis: Data from 20 Countries}

\author{
Xiaodong Cai* and David W. Brown
}

\author{
3 United Nations Plaza, New York, NY 10017, USA
}

Since the global economic and food price crisis began in the second half of 2008, there have been widespread concerns of considerable impact on child undernutrition $[1,2]$ as well as impacts on employment, poverty, and other development indicators associated with child undernutrition $[3,4]$. Although concerns of deterioration of child nutritional status as a result of the global economic and food price crisis are warranted, whether available evidence supports such claims of impact at national levels remains unclear. Using national survey data from 20 countries, we examined one dimension of the crisis at the individual child level by comparing nationally representative estimates of child nutritional status (i.e., stunting and underweight) before and after 2008 (Table 1).

We compiled data available through July 2010 from a global database maintained by the United Nations Children's Fund (UNICEF), the lead agency responsible for the global monitoring of the child-related Millennium Development Goals (MDGs). UNICEF plays a central role in monitoring the situation of children and women globally by assisting countries in the collection and analysis of data, helping to develop methodologies and indicators, maintaining global databases, and disseminating and publishing internationally comparable data. Countries included in the analysis were selected if anthropometry data were available for both the period 2002-2007 and 2008-2009. An independent sample student t-test with an alpha-level set at 0.05 was carried out for each country to compare prevalence estimates before and after 2008. In addition, estimates of child nutritional status were compared before and after 2008 among children from the poorest $20 \%$ of households to examine whether the nutritional impact, if any, was different from the national aggregates in the respective countries. (N.B.: Due to space constraints, a data table is not presented here but available from the authors upon request.)

Our review found that among 20 countries with comparable data, only one country had a modestly, yet statistically significant, higher stunting prevalence after the crisis than before the crisis (Fig. 1). Stunting, defined as height for age below minus two standard deviations from the median height for age of the standard reference population, is a measure of

*Address correspondence to this author at the 3 United Nations Plaza, New York, NY 10017, USA; Tel: +1.212.824.6553; E-mail: xcai@unicef.org chronic undernutrition, and more accurately reflects nutritional deficiencies and illness that occur during the most critical periods for growth and development early in life. Three countries showed a pattern of slightly higher prevalence after the crisis, but the increases were not statistically significant. In fact, many countries showed decreases in stunting prevalence after 2008. Although not graphically shown, similar patterns were observed among children from the poorest $20 \%$ of households.

Similarly, among 19 countries with comparable data on underweight prevalence (Fig. 2), defined as weight for age below minus two standard deviations from the median weight for age of the standard reference population, only one country showed a statistically significant increase from before to after the crisis, while four countries showed modest increases that were not meaningfully different than prior estimates. Again, many countries showed decreases after 2008.

While not a focus of our review, we reviewed data for wasting, defined as weight for height below minus two standard deviations from the mediation weight for height of the standard reference population (data not shown). While wasting reflects recent undernutrition, one must be cautious when considering patterns in wasting prevalence over time data as this measure is sensitive to seasonality such that estimates can fluctuate simply due to data being collected at different times of the year rather. Our review of wasting prevalence data for 19 countries with comparable estimates observed an increase in wasting prevalence in Ghana (from 6\% [data collected August to October 2006] to 9\% [data collected September to November 2008]) and in Sao Tome and Principe (from $8 \%$ [data collected May to June 2006] to 11\% [data collected September 2008 to March 2009]).

Unlike other development indicators that can be estimated from administrative data, such as employment or agriculture production, child undernutrition estimates rely almost entirely on anthropometric data collected from household surveys (e.g., Demographic and Health Survey or Multiple Indicator Cluster Survey). Anthropometric survey data are subject to both systematic and random error and may arise out of inadequate and improper training of field staff, difficulties of measurement in the field, as well as instrumental or technical errors. The survey data included here provide a useful, albeit limited, snap-shot of the early period after the global economic and food crisis. It is possible that any 
Table 1. Selected Countries with Anthropometry Data from Nationally Representative Surveys, 2002 - 2009

\begin{tabular}{|c|c|c|c|c|}
\hline & Data year & Underweight (\%) & Stunting (\%) & Source \\
\hline Albania & 2008-2009 & 5 & 19 & DHS \\
\hline Albania & 2005 & 6 & 26 & MICS \\
\hline Bolivia & 2008 & 4 & 27 & DHS \\
\hline Bolivia & 2003 & 5 & 32 & DHS \\
\hline Burkina Faso & 2009 & 26 & 35 & NNS \\
\hline Burkina Faso & 2006 & 32 & 41 & MICS \\
\hline Cambodia & 2008 & 29 & 40 & NNS \\
\hline Cambodia & 2005 & 28 & 42 & DHS \\
\hline Egypt & 2005 & 5 & 23 & DHS \\
\hline Egypt & 2008 & 6 & 29 & DHS \\
\hline Georgia & 2009 & 1 & 11 & NNS \\
\hline Georgia & 2005 & 2 & 13 & MICS \\
\hline Ghana & 2008 & 14 & 28 & DHS \\
\hline Ghana & 2006 & 13 & 28 & MICS \\
\hline Guinea & 2008 & 21 & 40 & NNS \\
\hline Guinea & 2005 & 22 & 39 & DHS \\
\hline Guyana & 2009 & 11 & 18 & DHS \\
\hline Guyana & 2006 & 10 & 17 & MICS \\
\hline Jordan & 2009 & 2 & 8 & DHS \\
\hline Jordan & 2002 & 4 & 12 & DHS \\
\hline Kenya & 2008-2009 & 16 & 35 & DHS \\
\hline Kenya & 2003 & 16 & 36 & DHS \\
\hline Lesotho & 2009 & 14 & 39 & DHS \\
\hline Lesotho & 2007 & 14 & 42 & NNS \\
\hline Madagascar & 2008-2009 & $::$ & 50 & DHS \\
\hline Madagascar & 2003-2004 & $::$ & 53 & DHS \\
\hline Mauritania & 2009 & 14 & 23 & NNS \\
\hline Mauritania & 2007 & 25 & 32 & MICS \\
\hline Mozambique & 2008 & 18 & 44 & MICS \\
\hline Mozambique & 2003 & 20 & 47 & DHS \\
\hline Niger & 2009 & 34 & 46 & NNS \\
\hline Niger & 2006 & 39 & 55 & DHS \\
\hline Peru & 2009 & 4 & 24 & DHS \\
\hline Peru & 2004-2006 & 6 & 30 & DHS \\
\hline Sao Tome & 2008-2009 & 13 & 29 & DHS \\
\hline Sao Tome & 2006 & 7 & 29 & DHS \\
\hline Sierra Leone & 2008 & 21 & 36 & DHS \\
\hline Sierra Leone & 2005 & 25 & 45 & MICS \\
\hline Zimbabwe & 2009 & 12 & 35 & MIMS \\
\hline Zimbabwe & $2005-2006$ & 12 & 33 & DHS \\
\hline
\end{tabular}

DHS: Demographic and Health Survey.

MICS: Multiple Indicator Cluster Survey.

MIMS: Multiple Indicator Monitoring Survey.

NNS: National Nutrition Survey. 


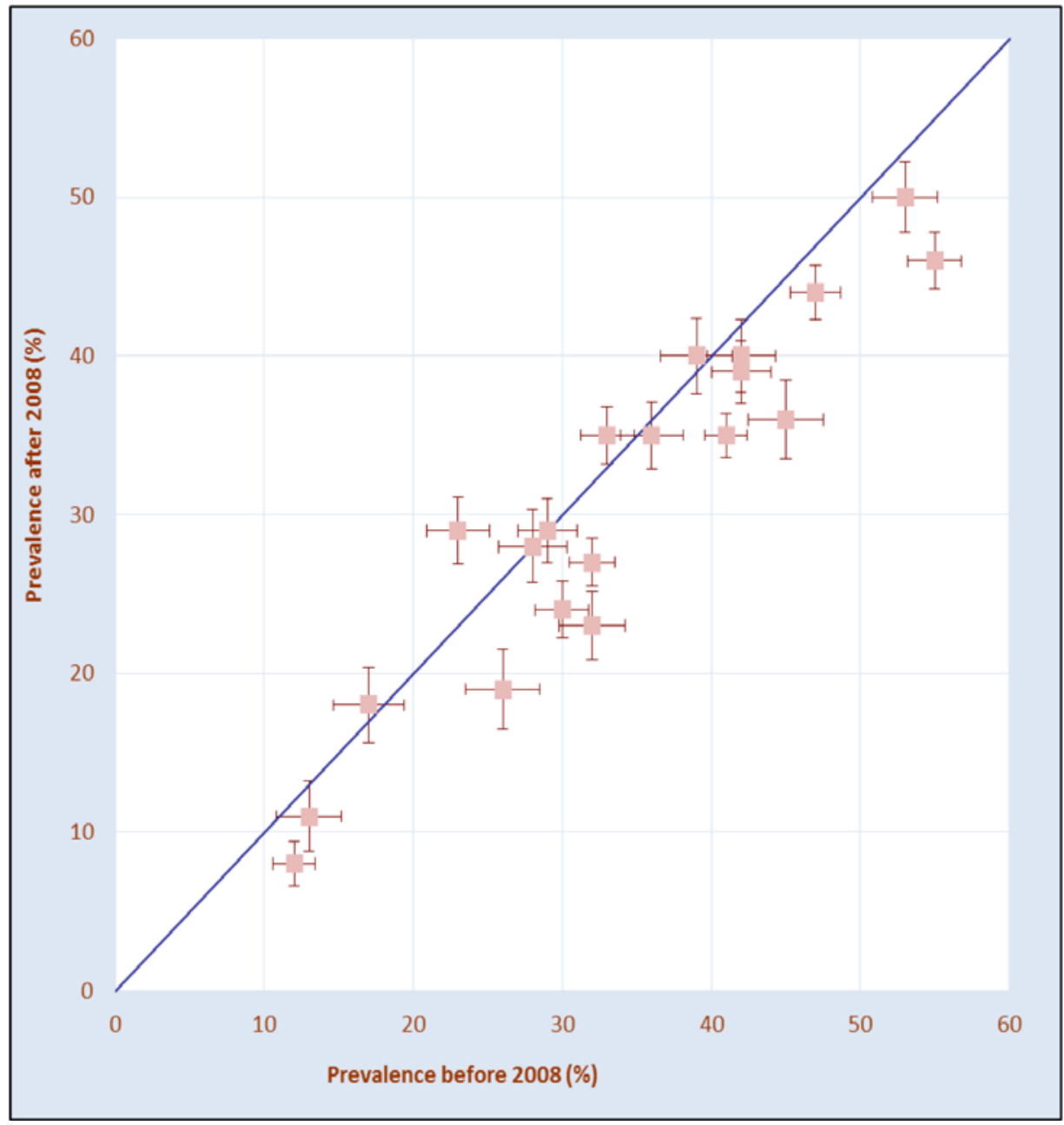

Fig. (1). Stunting prevalence before and after 2008, selected countries.

Note: Prevalence estimates are reported according to WHO Child Growth Standards. Error bars represent $95 \%$ confidence intervals of these estimates.

Source: DHS, MICS and national nutrition surveys 2002 - 2009 from countries with comparable data.

effects of the global economic and food crisis did not manifest themselves in measures of underweight and stunting until beyond the period captured here.

Our aim here is to highlight the need for caution when considering the potential impact(s) of the global economic and food price crisis on child undernutrition. To fully explain the lack of deterioration in child undernutrition as an impact of the crisis at the individual level would be an overly ambitious goal for a communication like this. Nonetheless, potential explanations, which require further study, include the following.

\section{Child-Favorable Allocation of Resources}

Although recent estimates suggest sharp increases in the number of people suffering from hunger in 2009, compared to levels in 2008 [5], it is important to note that not everyone in a household is equally hit by crises in terms of food insecurity and health care. For example, parents might divert resources for food, health and care to children to buffer the shock on the most vulnerable in the household. Simultaneous examination of women's nutritional status from the same surveys may improve our understanding of such reallocation.

\section{Substitution of Quality Food}

With limited financial resources, people may switch from expensive protein-rich and micronutrient-rich foods to cheaper energy-rich foods. In the short-run, this may buffer weight loss in children but in the long-run, this may result in a lack of gain in height, i.e., higher prevalence of stunting. However, consequences such as these might not have been captured by the most recent surveys but may be reflected in future ones.

\section{Slower Rates of Reduction Toward Country Goals}

Instead of a complete reversal of a country's progress in reducing child undernutrition made before the crisis, it might have slowed progress, resulting in an attenuated rate of reduction. An examination of country-specific trends of undernutrition over the past 10 to 15 years may improve our understanding of the crisis on country progress.

\section{Differential Impact on Sub-National Population}

National averages may mask disparities at sub-national levels. For example, it has been reported that wasting prevalence among the urban poor in Cambodia has increased from 


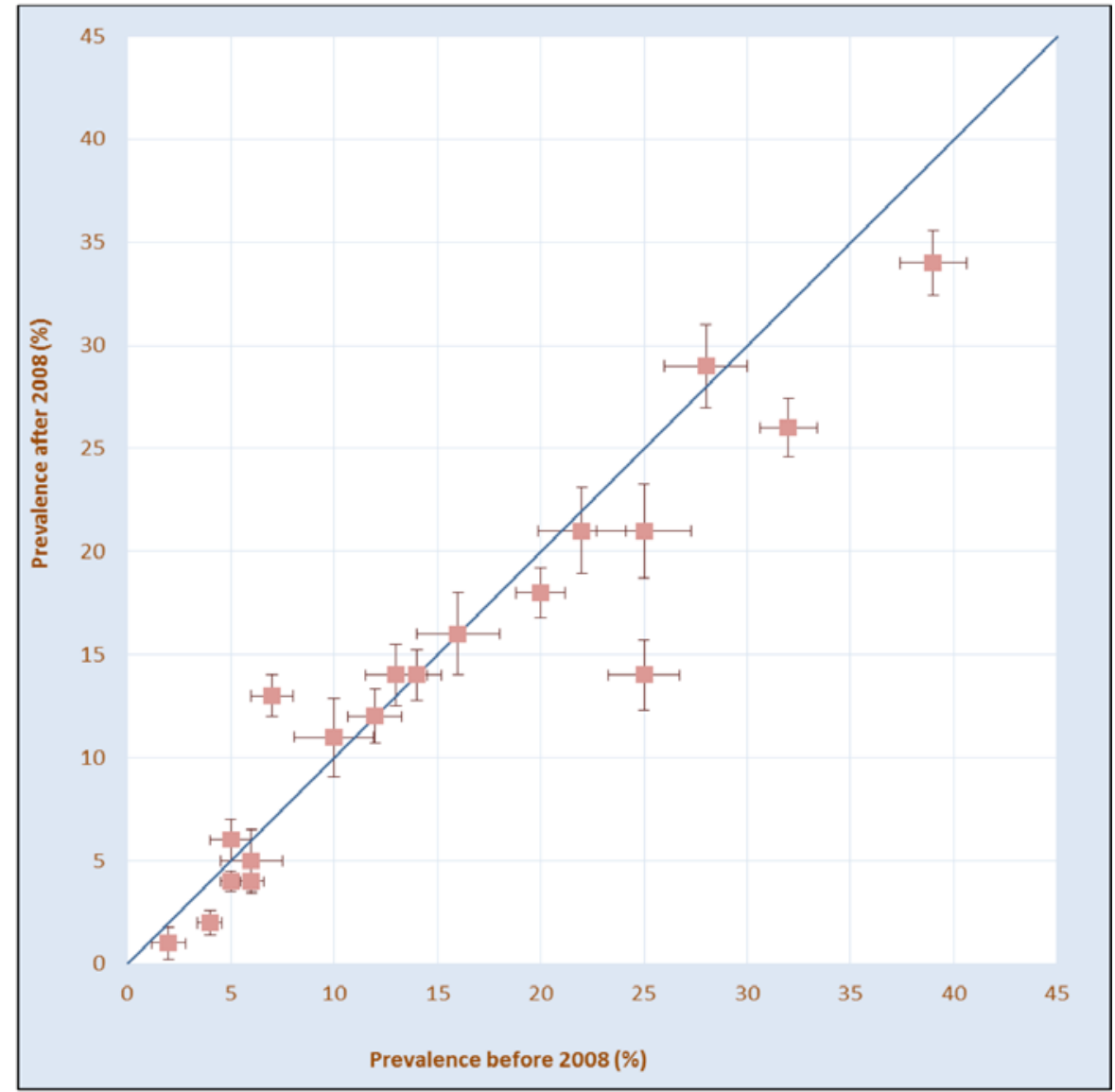

Fig. (2). Underweight prevalence before and after 2008, selected countries.

Note: Prevalence estimates are reported according to WHO Child Growth Standards. Error bars represent $95 \%$ confidence intervals of these estimates.

Source: DHS, MICS and national nutrition surveys 2002 - 2009 from countries with comparable data.

$10 \%$ in 2005 to $16 \%$ in 2008 [6]. We examined the prevalence among children from the poorest households, but they may not necessarily be the most vulnerable in some countries where the poor were actually the target of donor assistance programs. In such situations, undernutrition might not have worsened differentially by poverty status but by some other factors.

In summary, we highlight a lack of current evidence for deterioration in child undernutrition in 20 countries with comparable national data before and after 2008. This is not to state that claims, concerns and predictions of a deteriorating situation are inaccurate in all areas or that such may not hold true in the future; rather, the available evidence on child underweight and stunting at the national level in a select set of countries does not support claims and predictions of widespread impact that we have observed. Moreover, we caution against making such causal links without adequate evidence and encourage a renewed focus on correcting current deficiencies in the available evidence at global, regional and country levels and further improving evidence-based decision making at each of these levels [7].

\section{DISCLAIMER}

The opinions expressed herein are those of the author(s) alone and do not necessary reflect those of the United Nations Children's Fund.

\section{CONFLICT OF INTEREST}

None to declare.

\section{REFERENCES}

[1] United Nations System Standing Committee on Nutrition. Global recession increases malnutrition for the most vulnerable people in developing countries. 2009. [cited 2010 Aug 20] Available from http://www.unscn.org/files/Publications/Briefs_on_Nutrition/SCN_ Nutrition_Impacts_of_Financial_Crisis_4p.pdf

[2] Voice of America. UN: World Recession Raising Malnutrition Death Rates. 2009. [cited 2010 Aug 20] Available from http:// www.voanews.com/english/news/a-13-2009-09-01-voa1768708977.html

[3] The World Bank. The World Bank Group's Response to the Global Economic Crisis. Washington, DC: The World Bank, 2010. Available from http://nweb90.worldbank.org/oed/oeddoclib.nsf/ DocUNIDViewForJavaSearch/908B015F08B1E2B1852577F900547 D6A/\$file/Global_Econ_Crisis-full.pdf [accessed 18 July 2011].

[4] The World Bank. Global Monitoring Report 2010: The MDGs after the Crisis. Washington, DC: The World Bank, 2010. Available from: http://go.worldbank.org/8NMBGII280 [accessed 18 July 2011].

[5] Food and Agriculture Organization. 2010. Global hunger declining, but still unacceptably high. [cited 2010 Aug 20] Available from http://www.fao.org/docrep/012/al390e/al390e00.pdf

[6] Cambodia National Institute of Statistics and UNICEF. Cambodia Anthropometrics Survey. 2009. [cited 2010 Aug 20] Available from

http://www.unicef.org/socialpolicy/files/Cambodia_Anthropometri cs_Survey.pdf 
[7] Benson T, Minot N, Pender J, Robles M, von Braun J. Global Food Crises: Monitoring and Assessing Impact to Inform Policy
Responses. Washington, D.C.: International Food Policy Research Institute, September 2008.

(C) Cai and Brown; Licensee Bentham Open

This is an open access article licensed under the terms of the Creative Commons Attribution Non-Commercial License (http://creativecommons.org/licenses/by-nc/3.0/) which permits unrestricted, non-commercial use, distribution and reproduction in any medium, provided the work is properly cited. 